\title{
Sluggish US employment recovery after the Great Recession: Cyclical or structural factors?
}

\author{
Marcella Lucchetta*, Antonio Paradiso \\ University of Venice Ca' Foscari, Department of Economics, Italy
}

\section{A R T I C L E I N F O}

\section{Article history:}

Received 20 January 2014

Accepted 29 January 2014

Available online 6 February 2014

\section{JEL classification:}

J21

E32

C40

\section{Keywords:}

Okun's law

Employment recovery

Cointegration

Structural and cyclical factors

\begin{abstract}
A B S T R A C T
This paper aims at investigating the causes of the observed departure of employment path from the GDP movements occurred in US in the late of 2008 onwards. Starting from a production function approach, and assuming that the TFP growth is explained by variables linked to the business cycle, we are able to formulate an extended version of Okun's law based on cyclical factors. Out-of-sample forecasting for the period 2008 onward shows that predicted US employment is on average $1.7 \%$ above the observed one, meaning that this gap cannot be attributed to identified cyclical factors.
\end{abstract}

(c) 2014 Elsevier B.V. All rights reserved.

\section{Introduction}

One of the macroeconomics "core ideas" that had been empirically confirmed before the recent crisis is Okun's law (Blinder, 1997). This simple rule-of-thumb suggested a relation between unemployment (or employment) and GDP (Okun, 1962). Economic predictors and policy makers frequently used this rule to assess the evolution of employment using GDP forecasts. From the late of 2008, however, the path of employment exhibits important departures from the GDP movements (Daly and Hobijn, 2010; Elsby et al., 2010; Bernanke, 2012). Fig. 1 shows the growth rates of US employment against GDP over the period 1970Q1-2013Q2. From 2008Q4 employment growth is below the regression line (i.e. employment is overpredicted) and continued on into the recovery period.

The empirical employment-GDP discrepancy raises an important question about the causes, as highlighted by Bernanke (2012): Is the low level of employment primarily the result of pronounced dip in cyclical factors (i.e. shift in aggregate demand and/or cyclical variables such as wages, prices, capacity utilization, etc.)? Or is instead the result of structural factors (i.e. mismatch between supply and demand for jobs caused by the presence of unskilled workforce, offshoring of manufacturing, low labor mobility, etc.)? Understanding the sources of this divergence

\footnotetext{
* Corresponding author.

E-mail addresses: lucchett@unive.it (M. Lucchetta), antonio.paradiso@unive.it (A. Paradiso).
}

raises important policy implications. If shifts in economic conditions predominate, then fiscal and monetary policies should be effective in supporting the employment recovery; if the causes are structural, then other policy measures are needed, such as programs to retrain workers or to promote their mobility towards areas where jobs exist.

This paper aims at investigating the causes of the employment-GDP empirical failure in the aftermath of the 2008's crisis going deeper into the characteristics of Okun's relation. We start from a classical log-levels version of the production function and evaluate the impact of GDP and TFP on employment. The idea is that through the well-known "capitalization effect" (i.e. technological progress favors employment by generating opportunities for profits) the TFP growth increases jobs creation, as demonstrated by Pissarides and Vallanti (2007) for US labor market.

We assume that the movement of TFP is captured by trade openness and the ratio of wages to machinery prices. In general, trade openness favors the circulation of ideas, knowledge and technologies, affecting in this way the TFP. Since openness may present non-monotonic (U-shaped) impact on growth (see RiveraBatiz and Romer, 1991; Baldwin and Forslid, 1999), we introduce a quadratic term for openness into the regression as in Edwards (1998). The wages expressed in terms of machinery prices (i.e. the factors price ratio) affect the pace of mechanization and technical progress; when labor is more expensive than capital, there is an incentive to introduce a technological innovation (Acemoglu, 2003).

Since all the variables (i.e. employment, GDP, trade openness and wages to machinery prices ratio) are non-stationary in 
log-levels, we estimate a long-run relationship using the Dynamic OLS (DOLS) approach. The ECM version of this model is then compared to other specifications of Okun's law considered in the empirical literature. Our model performs better compared to alternative specifications of Okun's law in explaining the sluggish pattern of employment after the 2008. Since our model is based exclusively on variables linked to the business cycle, the misprediction of the employment (1.7\% on average) may be attributable to structural factors.

The paper is organized as follows. Section 2 presents our model specification, Section 3 shows the estimation results and the comparison of our model with other alternative versions in terms of the employment explanation after 2008. Section 4 concludes.

\section{Model specification}

We start by considering the following production function:

$Y_{t}=A_{t} K_{t}^{\alpha} L_{t}^{\beta}$

where $A$ is the stock of knowledge, $Y$ is the output, $K$ is the capital stock and $L$ is the number of employers.

We assume that $A_{t}=A_{0} e^{g_{t}}$, where $A_{0}$ is the initial Total Factor Productivity (TFP) and $g_{t}$ is the growth rate of $A$. We can specify the evolution of $A$ by making $g$ a function of trade openness (open, the sum of imports and exports as a percentage of GDP) and wages to machinery prices ratio ( $\mathrm{wm}$, wages as a percentage of implicit price deflator for fixed investment in equipment and software):

$g_{t}=\phi_{1}$ open $_{t}+\phi_{t}$ open $_{t}^{2}+\delta w m_{t}$

where open is assumed to be nonlinear to capture non-monotonic (U-shaped) effects on growth (Edwards, 1998). In this regard, we expect that $\phi_{1}<0$ and $\phi_{2}>0$, so that the turnaround value corresponds to $\left|\phi_{1} /\left(2 \phi_{2}\right)\right|$. Substituting (2) in (1) and taking the logs, we obtain:

$y_{t}=a_{0}+\phi_{1}$ open $_{t}+\phi_{2}$ open $_{t}^{2}+\delta w m_{t}+\alpha k_{t}+\beta l_{t}$.

Okun's law in terms of employment-output relation can be written as:

$l_{t}=\varphi_{0}+\varphi_{1} y_{t}$.

Substituting (3) in (4):

$l_{t}=\varphi_{0}+\varphi_{1}\left(a_{0}+\phi_{1}\right.$ open $_{t}+\phi_{2}$ open $\left._{t}^{2}+\delta w m_{t}+\alpha k_{t}+\beta l_{t}\right)$.

If we assume that $k$ is a linear function of $y$ (i.e. $k_{t}=v_{1}+v_{2} y_{t}$ ) as supposed by the accelerator model, after some algebraic manipulations we obtain the following expression:

$l_{t}=\theta+\omega_{1}$ open $_{t}+\omega_{2}$ open $_{t}^{2}+\psi w m_{t}+\gamma y_{t}$

where $\theta=\frac{\left[\varphi_{0}+\varphi_{1}\left(a_{0}+\alpha v_{1}\right)\right]}{\left(1-\varphi_{1} \beta\right)}, \omega_{1}=\frac{\varphi_{1} \phi_{1}}{\left(1-\varphi_{1} \beta\right)}, \omega_{2}=\frac{\varphi_{1} \phi_{2}}{\left(1-\varphi_{1} \beta\right)}, \psi=$ $\frac{\varphi_{1} \delta}{\left(1-\varphi_{1} \beta\right)}$ and $\gamma=\frac{\varphi_{1} \alpha v_{2}}{\left(1-\varphi_{1} \beta\right)}$.

Eq. (6) represents the long run relation. The ECM form can be written as follows:

$$
\begin{aligned}
\Delta l_{t}= & -\lambda\left(l_{t-1}-\left(\theta+\omega_{1} \text { open }_{t-1}+\omega_{2} \text { open }_{t-1}^{2}\right.\right. \\
& \left.\left.+\psi w m_{t-1}+\gamma y_{t-1}\right)\right)+\sum_{k=1}^{n_{1}} m_{k} \Delta l_{t-k} \\
& +\sum_{k=0}^{n_{2}} p_{k} \Delta \text { open }_{t-k}+\sum_{k=0}^{n_{3}} q_{k} \Delta \text { open }_{t-k}^{2} \\
& +\sum_{k=0}^{n_{4}} v_{k} \Delta w m_{t-k}+\sum_{k=0}^{n_{5}} z_{k} \Delta y_{t-k}+\varepsilon_{t} .
\end{aligned}
$$

\section{Estimation results and model performance}

To estimate the model in Eqs. (6)-(7), we use the data (covering the period 1970Q1-2013Q2) taken from Federal Reserve Economic Data (FRED). All data expressed in log-levels (emp and $y$ )

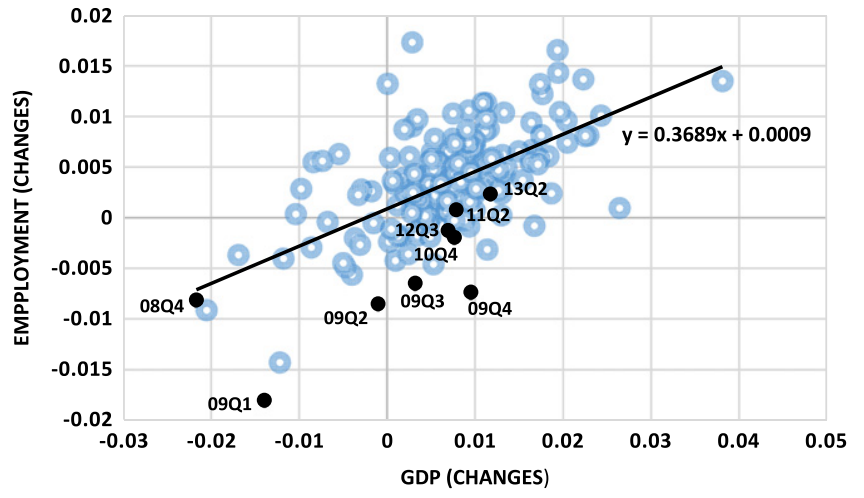

Fig. 1. Quarter on quarter growth rate of employment against GDP, 1970Q12013Q2. Black circles denote observations below the regression line in the aftermath of 2008's crisis.

Source: Author's calculation using FRED data.

and as a ratio (open, open ${ }^{2}$ and $w m$ ) are non-stationary over the period under investigation ${ }^{1}$ and for this reason we study the presence of a long-run relation. We first estimate the long-run relationship of Eq. (6) using DOLS. This estimator deals with the problem of second-order asymptotic bias arising from serial correlation and endogeneity and is asymptotically efficient; in addition, DOLS performs better in finite samples compared to other asymptotically efficient estimators (Montalvo, 1995). Then, we estimate the ECM (Eq. (7)) with the long-run relation and we study the factor loading $(\lambda)$ and the tests for correct specification.

Results are presented in Table 1. The long-run relation (Eq. (6)) exhibits statistically significant coefficients and the residuals cointegration test (ADF) confirms the existence of a long-run relationship. The nonlinear estimation of open produces a turnaround value of $0.244(=3.11 /[2(6.36)])$; this nonlinear pattern is plotted in Fig. 2 (panel a). The ECM form (Eq. (7)) exhibits a factor loading $(\lambda)$ negative and statistically significant; the diagnostic tests are satisfactorily confirming that the model is correctly specified. In Fig. 2 we also report a graphical representation of additional estimation results.

Having established the correct specification of our model, we perform an out-of-sample forecasting for the period of sluggish growth in employment (i.e. 2008Q2-2013Q2). The estimation is stopped in 2008Q1 and a forecast for the period until the end of sample is run. In Fig. 3 we compare our model (labeled as "DOLS") with different versions of Okun's law considered in the literature: Okun's classical regression in first difference $(O K U N)$; dynamic version of Okun's law (OKUN DYN); Okun's law with GAP specification (OKUN GAP). Our model exhibits very accurate forecasts for employment over the period of sluggish employment growth, outperforming other models and showing a lower RMSE respect to these compared versions.

The extent of misprediction of our model is low. Employment is over-predicted by $1.7 \%$ (on average) over all the forecast period 2008Q2-2103Q2. One may conclude that this gap represents the extent part of employment that is reduced by structural factors, since our model is based only on business cycle factors. Given that this misprediction depends mainly on structural factors, ${ }^{2}$ eliminating this employment shortfall will depend on the introduction of appropriate policy measures such as programs to retrain workers or to promote their mobility towards areas where jobs exist.

\footnotetext{
1 The unit-root tests are available from authors upon request.

2 The misprediction incorporates both structural factors and model uncertainty.
} 

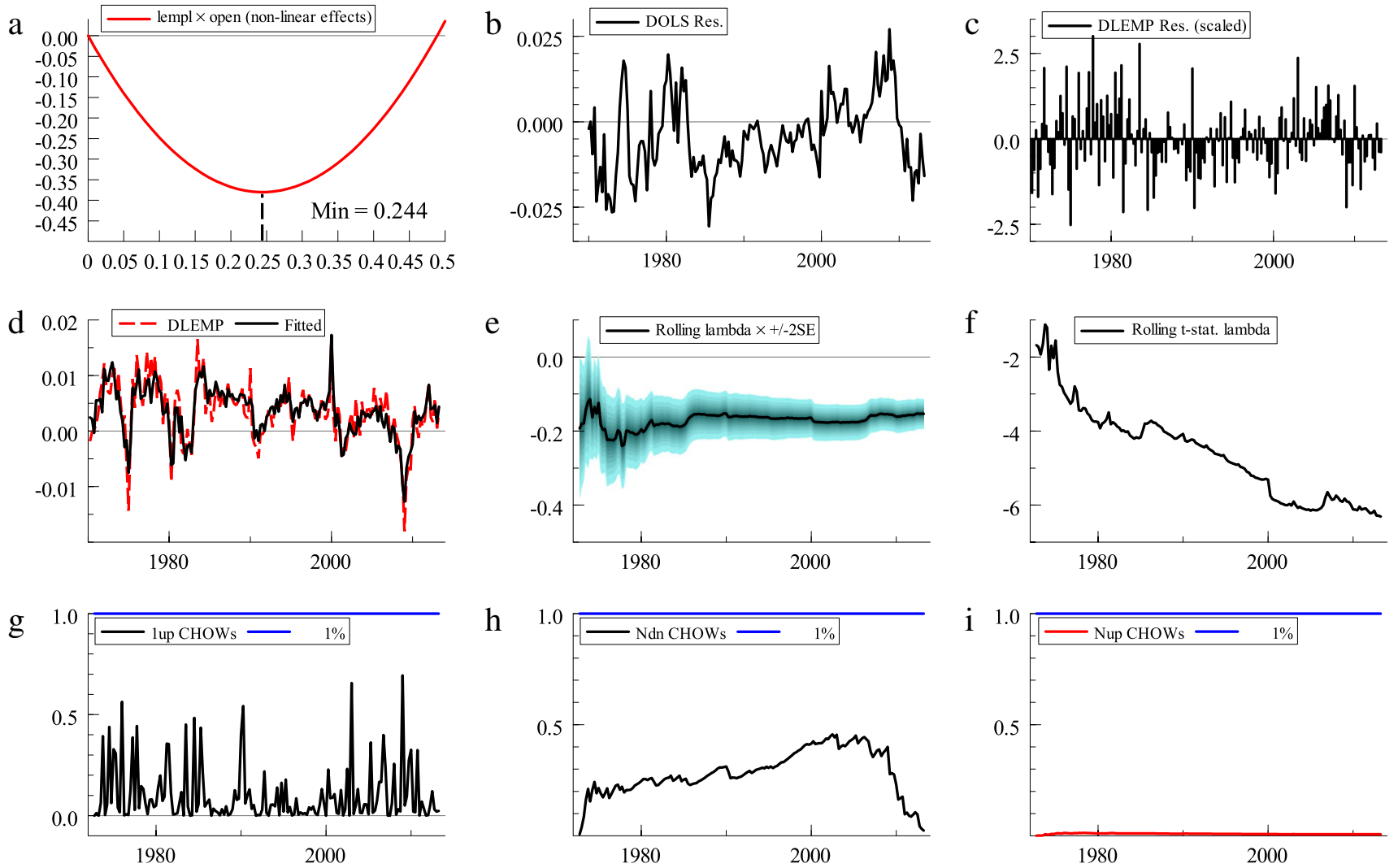

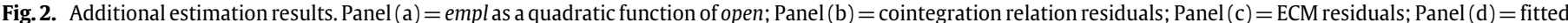

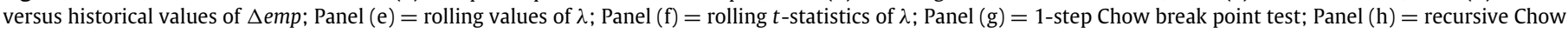
break point test; Panel $(\mathrm{i})=$ recursive Chow forecast test.
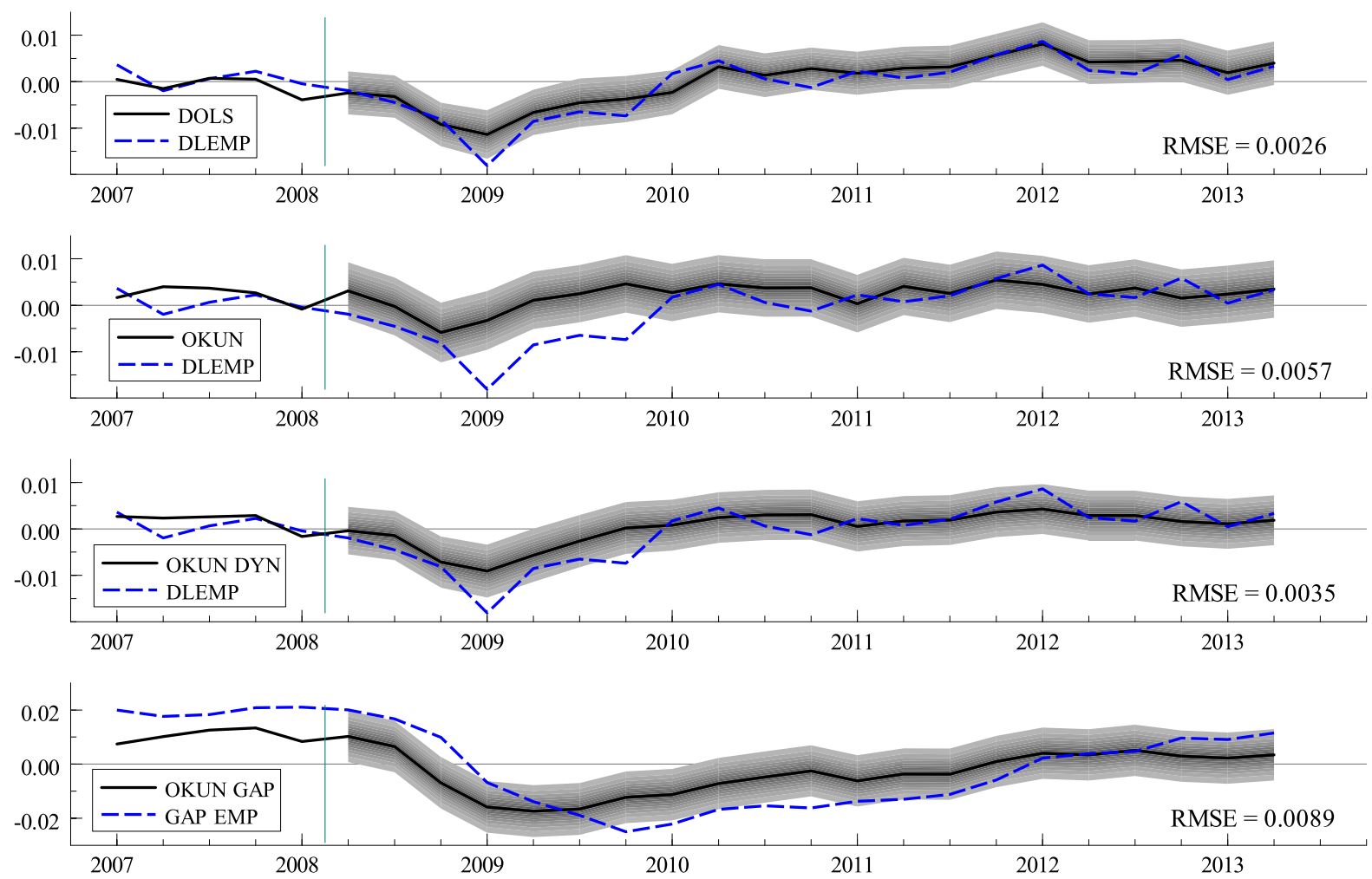

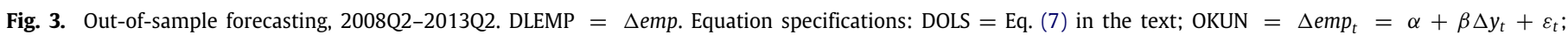

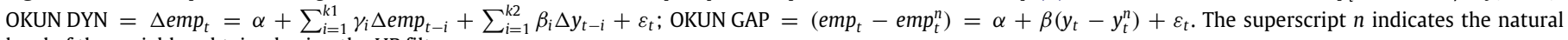
level of the variables obtained using the HP filter. 
Table 1

DOLS estimates for employment, 1970Q1-2013Q2.

\begin{tabular}{|c|c|}
\hline$\theta$ & $\begin{array}{l}4.005 \\
(0.190)\end{array}$ \\
\hline$\omega_{1}$ & $\begin{array}{r}-3.111 \\
(0.449)\end{array}$ \\
\hline$\omega_{2}$ & $\begin{array}{l}6.364 \\
(1.120)\end{array}$ \\
\hline$\psi$ & $\begin{array}{r}-0.383 \\
(0.033)\end{array}$ \\
\hline$\gamma$ & $\begin{array}{l}0.897 \\
(0.026)\end{array}$ \\
\hline$\lambda$ & $\begin{array}{r}-0.153 \\
(0.024)\end{array}$ \\
\hline Res. ADF coint. test & $-4.568^{*}$ \\
\hline$R^{2}$ adj. (ECM) & 0.728 \\
\hline$\hat{\sigma}$ & 0.003 \\
\hline \multicolumn{2}{|l|}{ Diagnostic tests } \\
\hline AR $1-5$ test ( $p$-value) & 0.571 \\
\hline ARCH $1-4$ test ( $p$-value) & 0.249 \\
\hline Norm. test ( $p$-value) & 0.156 \\
\hline Hetero-test ( $p$-value) & 0.070 \\
\hline Hetero- $X$ test ( $p$-value) & 0.061 \\
\hline RESET test ( $p$-value) & 0.124 \\
\hline
\end{tabular}

Notes: The number in parentheses is HAC standard errors with Bartlett kernel of bandwidth parameter 5 . Leads and lags in DOLS estimate are selected according to the SIC criteria. Res. ADF is the residual-based cointegration test. $\lambda$ is the factor loading of the ECM term. A spike dummy (2000Q1) is added in ECM (peak in US labor force). The numbers of lags $n_{1}, n_{2}, n_{3}, n_{4}, n_{5}$ in ECM are selected using Autometrics in PcGive and are not reported for brevity. Diagnostic tests: $A R 1-n$ is the Harvey test for $n$th order serial autocorrelation; Norm test is the Doornik-Hansen normality test; $A R C H$ 1-4 is the Engle test for 4th order autoregressive conditional heteroskedasticity in the residuals; Hetero and Hetero- $X$ are the White test for residual heteroskedasticity with and without cross products, respectively; RESET is the Ramsey test for functional form misspecification.

Indicates significance at $5 \%$.

\section{Conclusions}

We estimate an extended version of Okun's law starting from a classical production function. TFP is assumed to be explained by trade openness and wages to machinery prices ratio. Using the Dynamic OLS (DOLS) approach, the ECM version of our model is then compared to other specifications of Okun's law considered in the empirical literature. Our model performs better in explaining the sluggish pattern of employment after the 2008. Since our model is based exclusively on variables linked to the business cycle, the misprediction of the employment ( $1.7 \%$ on average) may be attributable to structural factors.

\section{Acknowledgment}

The authors acknowledge financial support under the project MISURA, funded by the Italian MIUR.

\section{References}

Acemoglu, D., 2003. Factor prices and technical change: from induced innovations to recent debates. In: Aghion, P., et al. (Eds.), Knowledge, Information and Expectations in Modern Macroeconomics: In Honor of Edmund Phelps. Princeton University Press, Princeton, NJ.

Baldwin, R.E., Forslid, R., 1999. Incremental trade policy and endogenous growth: a $q$-theory approach. J. Econom. Dynam. Control 23, 797-822.

Bernanke, B.S., 2012. Recent developments in the labor market. In Speech Delivered at the National Association for Business Economics Annual Conference, Washington, March, Vol. 26.

Blinder, A.S., 1997. Is there a core of practical macroeconomics that we should all believe? Amer. Econ. Rev. 87, 240-243.

Daly, M., Hobijn, B., 2010. Okun's law and the unemployment surprise of 2009. FRBSF Econ. Lett. 7

Edwards, S., 1998. Openness, productivity and growth: what do we really know? Econom. J. 108, 383-398.

Elsby, M.W., Hobijn, B., Sahin, A., 2010. The labor market in the Great Recession. Brookings Papers on Economic Activity, 41 (spring), pp. 1-69.

Montalvo, J.G., 1995. Comparing cointegrating regression estimators: some additional Monte Carlo results. Econom. Lett. 48, 229-234.

Okun, A.M., 1962. Potential GNP: its measurement and significance. In: Proceedings of the Business and Economic Statistics Section. American Statistical Association, pp. 98-104.

Pissarides, C.A., Vallanti, G., 2007. The impact of TFP growth on steady-state unemployment. Internat. Econom. Rev. 48, 607-640.

Rivera-Batiz, L., Romer, P., 1991. International trade with endogenous technological change. Eur. Econ. Rev. 35, 971-1002. 